\title{
Sofrimento espiritual, busca de sentido e espiritualidade
}

\author{
Spiritual suffering, search of meaning and spirituality \\ Sufrimiento espiritual, búsqueda de sentido y espiritualidad
}

\begin{abstract}
Anete Roese
Doutora em Teologia pela Escola Superior de Teologia, fez suas pesquisas sobre a dimensão terapêutica da religião, é professora adjunta da Pontifícia Universidade Católica de Minas Gerais (PUC Minas), Belo Horizonte, MG - Brasil, e-mail: anete@luteranos.com.br

\section{Resumo}

O presente texto faz uma análise da situação espiritual de nossa época. Trata da angústia, da falta de sentido e do adoecimento espiritual como manifestações típicas do sofrimento da nossa era e desta sociedade. 0 sofrimento espiritual da humanidade compõe o quadro de sintomas que denotam a alienação do ser humano, uma ansiedade espiritual profunda, a negação da dimensão espiritual e, por outro lado, uma busca de sentido e de espiritualidade autêntica. A busca pelo entendimento desse sofrimento e a busca por um sentido e por uma experiência espiritual é uma tarefa da qual a ciência ainda deverá se ocupar longamente, e é o campo de tangência deste texto. Um diálogo mais efetivo entre psicologia, teologia, filosofia e outras ciências é
\end{abstract}


fundamental para uma compreensão mais consistente da existência humana. Os autores de referência são Viktor Frankl, Paul Tillich e Jacob Levi Moreno.

Palavras-chave: Psicologia. Religião. Teologia. Sentido. Espiritualidade.

\section{Abstract}

This text analyses the spiritual situation of our time. It is about anxiety, lack of meaning and spiritual illness as typical manifestations of the suffering of our time and of this society. The spiritual suffering of humanity characterizes the frame of symptoms that shows the alienation of the human being, a deep spiritual anxiety, the denial of the spiritual dimension and, on the other hand, a search for meaning and authentic spirituality. The search for understanding this suffering and the search for meaning and for a spiritual experience is a task of what science will take care for a long time and it is the field of tangency of this text. A more effective dialogue between psychology, theo-logy, philosophy and other sciences is essential to a more consistent understanding of human existence. The authors of reference are Viktor Frankl, Paul Tillich and Jacob Levi Moreno.

Keywords: Psychology. Religion. Theology. Meaning. Spirituality.

\section{Resumen}

Este texto hace un análisis de la situación espiritual de nuestra época. Trata de la angustia, de la falta de sentido y del padecimiento espiritual como manifestaciones típicas del sufrimiento de nuestra era y de esta sociedad. El sufrimiento espiritual de la humanidad compone el cuadro de síntomas que denotan la alienación del ser humano, una ansiedad espiritual profunda, la negación de la dimensión espiritual y, por otro lado, una búsqueda de sentido y de espiritualidad auténtica. La búsqueda por la comprensión de este sufrimiento y la búsqueda por un sentido y por una experiencia espiritual es una tarea de la cual la ciencia aún deberá ocuparse largamente y es el campo de tangencia de este texto. Un diálogo más efectivo entre psicología, teología, filosofía y otras ciencias es fundamental para una comprensión más consistente de la existencia humana. Los autores de referencia son Viktor Frankl, Paul Tillich y Jacob Levi Moreno.

Palabras-clave: Psicología. Religión. Teología. Significado. Espiritualidad. 


\section{Introdução}

Espiritualidade é um tema em voga. Justamente em um tempo em que as religiões são muito questionadas como instituições, com seus dogmas, ritos e verdades. Por um lado, o ser humano parece haver perdido a fé; por outro, a cada dia surgem mais e novas igrejas e formas de crer e de viver a vida espiritual. O presente texto se dedicará a uma análise do contexto que leva a humanidade à desenfreada busca por espiritualidade ou religiosidade no contexto atual. O contexto em questão se refere à angústia, vacuidade, falta de sentido e ao sofrimento e adoecimento espiritual cuja expressão é única e típica de nossa era. Aqui, os principais autores de referência serão Viktor Frankl, Paul Tillich e Félix Guattari.

De início, porém, o texto abordará o debate sobre definições e diferenciações em torno dos conceitos fé, espiritualidade e religiosidade. Este debate se estabelece em um contexto em que o termo fé parece estar caindo em desuso e o termo espiritualidade cada vez mais substitui o conceito anterior. Esta abordagem será feita no contexto da teologia, da psicologia da religião e das ciências da religião.

Em um terceiro momento, o texto abordará possibilidades de reinvenção da subjetividade diante dessa angústia espiritual. $\mathrm{O}$ autor de referência será Jacob Levy Moreno, criador da psicoterapia psicodramática, que faz uma bem-sucedida integração e um diálogo criativo entre a psicologia e a teologia.

\section{Fé, espiritualidade ou religiosidade?}

Não é possível negar que o termo espiritualidade ganhou espaço na última década. Na academia, nos títulos de livros e artigos e até mesmo no contexto popular o termo vem sendo preferido, em detrimento do conceito fé e religiosidade. Vários autores já discutem a opção e a origem dessa "moda". João Edênio Valle (2005) chama a nossa atenção para a tendência que vem dos EUA - a de substituir o termo religiosidade por espiritualidade -, e lembra que corremos o mesmo perigo se caímos na tentação de "chamar tudo de espiritual". De todo modo, é importante que 
neste momento de reflexão possamos compreender melhor do que se trata e do que falamos quando nos ocupamos desse campo da espiritualidade. Será que podemos falar de sinônimos quando falamos de espiritualidade, religiosidade e fé? De certo modo, sim, dependendo do que entendemos por cada um. Poderíamos perguntar se todo ser humano é espiritual ou se toda religiosidade é espiritual. Vejamos como podemos destrinchar isso.

Valle (2005, p. 101) afirma que espiritualidade "expressa o sentido profundo do que se é e se vive de fato". Permite que o ser humano ultrapasse o estado biológico e emocional de suas vivências. Segundo Heschell, afirma que "a existência humana está impregnada de sintomas de transcendência e a abertura a ela é um elemento constitutivo do ser humano”.

A espiritualidade aqui é compreendida como elemento inerente ao ser humano. E a experiência religiosa, ou religiosidade, é um gênero específico de experiência espiritual. Segundo Valle, há experiência de sentido espiritual que não tem caráter religioso. Um ateu pode ser uma pessoa espiritualmente rica, porque são muitas as maneiras de se chegar à experiência de Deus. Todas as experiências criativas e profundas podem levar ao desvelamento da espiritualidade porque levam a uma percepção especial diante da vida.

Em seu estudo, Valle (2005, p. 104-105) contempla uma série de outros importantes significados de espiritualidade que merecem ser tomados em conta. Para ele, a noção de espiritualidade é uma "necessidade psicológica” própria do ser humano, que inclui busca de sentido para a existência e está "unida à motivação profunda que nos faz crer, lutar, amar". Ela está direcionada para "o porquê último da vida" que, no entanto, não se furta de questionamentos e compromissos inerentes à vida; é produto de "aprendizado" de ensinamentos da vida sobre "nossa humanidade", "dom gratuito que nos é oferecido em momentos privilegiados de nossa vida, que podemos ou não descobrir, aceitar e cultivar". Por último, Valle afirma que uma "espiritualidade adulta"

supõe conhecimento e aceitação dos próprios limites e possibilidades. Não é um ato de resignação e sim uma atitude corajosa e humilde de alguém que sabe que sua vida é um projeto aberto ao ser mais, ao comungar mais, ao cuidar do que precisa ser cuidado. É uma experiência de despojamento 
que se coloca nas antípodas do poder, da auto-suficiência e do imediatismo egocêntrico (VALLE, 2005, p. 105).

Há também experiências negativas que compõem a vivência espiritual. Nem toda espiritualidade é saudável, nem sempre conduz ao bem próprio e do próximo. Há espiritualidade que não tem valores profundos e que não leva ao amadurecimento.

Leonardo Boff (2009), em um texto intitulado "Espiritualidade, dimensão esquecida e necessária”, alerta para os reducionismos que envolvem a compreensão dualista que herdamos e que separa o espírito da matéria. Nesse caso, espiritualidade se constitui como uma parte do que somos e não raro é compreendida como a parte oposta à matéria, ao corpo, dividindo o ser humano em duas dimensões antagônicas. No contexto dessa compreensão, a espiritualidade é tratada como algo que se faz, uma prática de um momento, em algum lugar especial.

Para Boff (2009, p. 2), espiritualidade é mais que um momento ou uma prática situacional, é "um modo-de-ser". O ser humano é uma totalidade complexa, articulada e harmonizada, e não é composto por dimensões justapostas, muito menos antagônicas. Entre as dimensões múltiplas que compõem a totalidade do ser, o autor destaca três, a fim de compreender melhor o ser humano em sua complexidade: a exterioridade - dimensão corpórea/corporeidade -, que está muito além do corpo físico, engloba as relações todas, é o ser no mundo com seus sentimentos e seus dramas; a interioridade - dimensão psíquica -, que é uma "dinâmica ilimitada", "a totalidade do ser humano voltada para dentro", e que articula as motivações que chegam do mundo externo, envolve os desejos, as paixões, a capacidade criativa (é fundamental que o ser humano cuide dos seus desejos); e, finalmente, a dimensão da profundidade, que é a dimensão espiritual. Trata-se da capacidade do ser humano de ver para além das aparências e captar o sentido das coisas, os valores e os significados. É uma atitude, um modo-de-ser que está presente o tempo todo, não apenas em momentos de meditação. "Espírito não é uma parte do ser humano. É aquele momento da consciência mediante o qual captamos o significado e o valor das coisas. Mais ainda, é aquele estado de consciência pelo qual apreendemos o todo e a nós mesmos como parte e parcela deste 
todo" (BOFF, 2009, p. 3). A espiritualidade é a vivência dos valores mais profundos que o humano é capaz de expressar, é a realização mais plena do ser humano, é a manifestação da essência - o lugar onde o divino e o humano são uma única matéria.

Para o psiquiatra e neurologista Viktor Frankl (1905-1997), até o inconsciente tem uma dimensão espiritual. Trata-se de uma força criadora que precisa ser reabilitada, incluindo nele a ideia do espiritual. Nesse caso, a ideia de inconsciente está além do inconsciente impulsivo de Freud - um obscuro reservatório de instintos reprimidos. Para Frankl, o ser humano não é um ser impulsionado - ao contrário, é um ser que decide, é um ser responsável, existencial, que pode ser ele mesmo - mesmo nos estados inconscientes. O ser que decide é um ser centrado. O que compõe a sua centralidade são os atos espirituais, e é em torno do seu centro que se agrupa o psicofísico. Nesse sentido, o ser humano é um centro espiritual existencial. Um ser integrado: biopsicoespiritual. Uma totalidade.

A pessoa profunda, centrada, total, como centro da existência espiritual, foi por longo tempo negligenciada pela psicologia profunda. Frankl (1992) considera que a pessoa profunda é inconsciente, porque é espiritual-existencial. A responsabilidade, a capacidade de discernir e decidir são capacidades da instância espiritual. A dimensão religiosa, a dimensão intelectual e artística são forças primárias e dinamizadoras do inconsciente transcendental.

E o que poderíamos dizer sobre fé? Para o teólogo e filósofo Paul Tillich (1992, p. 7), séculos XIX-XX, "fé é o estado em que se é possuído por algo que nos toca incondicionalmente". Trata-se da "preocupação última”, isto é, da preocupação que nos toma plenamente, que nos orienta, que nos ocupa de forma suprema, ou aquilo com que o nosso ser está ocupado, e aquilo em que a nossa vida está centrada e que orienta a nossa vida. "Fé é um ato da pessoa como um todo". Por isso ela "participa da dinâmica da vida pessoal". E "é o ato mais íntimo e global do espírito humano". Ela tem sua raiz no centro da pessoa.

A fé nos capacita para sonhar com o infinito e a lidar com o finito. O ser humano é fascinado com a infinitude, seja com a infinitude de suas capacidades de ser e de criar e recriar a vida, seja por causa do sonho com uma vida infinita, sonho ilusório que impulsiona a esperança e a coragem 
de viver. O ser humano busca o infinito "porque o finito quer repousar no infinito. Porque no infinito ele vê a sua própria realização. Nisso é que se baseia a atração extática e a fascinação de tudo o que revela o infinito" (TILLICH, 1992, p. 13).

O infinito é o incondicional, quer dizer, é o que tem "validade última". A impossibilidade de tomar e prender o infinito leva à "inquietude do coração". A inquietude é propulsora da busca por sentido, busca pelas coisas que têm validade suprema, profunda e última. Essa inquietude promove e estimula a fé. A fé é a "paixão pelo infinito". A fé é uma possibilidade humana porque o ser humano é capaz de captar, desde a sua centralidade, a presença, a força e o sentido do infinito, do absoluto, do incondicional e do último. A fé como possibilidade, como dom, como algo do centro do ser é uma força e uma dimensão que quer se realizar, pois ela é a própria realização da plenitude do ser humano (TILLICH, 1992, p. 12).

James Fowler (1982, p. 89), em seus estudos sobre o desenvolvimento da fé do ser humano desde o seu nascimento, sustenta que

a fé é uma preocupação humana universal. Antes de sermos religiosos ou não-religiosos, antes de nos concebermos como católicos, protestantes, judeus ou muçulmanos, já estamos engajados em questões de fé [...] já estamos preocupados com as formas pelas quais ordenamos nossa vida e com o que torna a vida digna de ser vivida. Além disso, procuramos algo para amar, e que nos ame; algo para valorizar, e que nos dê valor; algo para honrar e respeitar, e que tenha o poder de sustentar nosso ser. [...] procuramos dar um sentido espiritual a nós mesmos.

Mais do que substituir um termo por outro, ou seguir um modismo no uso de termos, é importante analisar a qualidade da experiência que uma pessoa é capaz de ter. Destaca-se, no entanto, a compreensão de que a religiosidade é um modo específico de expressão espiritual. E que a espiritualidade é uma dimensão do humano que ultrapassa o desenvolvimento de uma religiosidade específica.

Viktor Frankl utiliza o termo religiosidade como sinônimo de fé. Compreende a religiosidade como a vivência desta, e entende que se trata de uma dimensão íntima, mais íntima que a própria sexualidade. A religiosidade, segundo o autor, está situada no âmbito da intimidade e é 
protegida pelo pudor. Há mais acanhamento para falar da religiosidade que para falar da sexualidade. E, como tal, pode ser reprimida. Assim como há uma libido inconsciente e reprimida, há também uma religiosidade inconsciente e reprimida.

Para Frankl (1992, p. 84), fé é uma maneira de pensar "à qual se acrescentou a existencialidade do pensador" (o fato de as luzes do palco ofuscarem a plateia não nos impede de crer que ela esteja lá). E religião pode ser definida como a realização de uma "vontade de sentido último". O ser humano tem a necessidade de "projetar" "algo ou alguém para dentro do nada diante do qual se encontra”. Um ser último não é apenas uma coisa. Nem tudo é o nada, o mesmo, o casual. Assim, o ser humano se ergue para sair da coisificação, do nada (eu). No entanto, "a religiosidade só é genuína quando existencial”, quando é a pessoa que se decide por ela, quando é espontânea. Não posso querer ter fé como não posso querer ou me obrigar a amar. É necessário um conteúdo e um objeto adequados para que a fé se realize, afinal, para que alguém creia é preciso tornar Deus crível. A fé é incondicional - permanece sob quaisquer condições ou não é fé.

\section{Vacuidade e angústia: falta de sentido e sofrimento espiritual}

O autor francês Félix Guattari, em seu livro As três ecologias, mostra que, ao lado das grandes transformações protagonizadas pelas sociedades humanas nesta era, a humanidade sofre grandes desequilíbrios, seja no meio ambiente natural, social, cultural ou subjetivo (interno). Guattari (1990, p. 1) pontua que

os modos de vida humanos individuais e coletivos evoluem no sentido de uma progressiva deterioração. As redes de parentesco tendem a se reduzir ao mínimo, a vida doméstica vem sendo gangrenada pelo consumo da mídia, a vida conjugal e familiar se encontra frequentemente "ossificada" por uma espécie de padronização dos comportamentos, as relações de vizinhança estão reduzidas a sua mais pobre expressão.

Para Viktor Frankl, criador da terceira escola vienense de psicoterapia - a logoterapia -, o que caracteriza esta época é um grande sentimento 
de vacuidade e insignificação, vazio e falta de sentido. Frankl (2003, p. 10) fala de "um processo crescente de adoecimento espiritual da sociedade", que se apresenta como uma neurose de massa, como um desespero diante de um imenso vazio, que pode ser verificado na violência, na depressão, no excesso de consumo de todo tipo de drogas, na banalização da sexualidade.

Segundo Frankl, a mais humana de todas as necessidades humanas é a necessidade de sentido, a vontade de sentido, e é essa vontade que hoje está tão frustrada no ser humano. O ser humano moderno está tomado por uma sensação de falta de sentido, que vem acompanhada de uma sensação de vazio interior, também denominada de vazio existencial, que se manifesta também por meio de tédio e indiferença. O tédio se revela na perda de interesse pelo mundo. A indiferença se manifesta na falta de iniciativa para melhorar ou modificar algo no mundo.

Frankl (1992) mostra que os índices de depressão, suicídio, agressão e violência; o uso de entorpecentes e a superficialidade com que são vividas dimensões tão íntimas como a sexualidade e a espiritualidade revelam justamente a fragilidade dos valores humanos e o profundo desespero e desânimo neste mundo. $O$ vazio existencial não é uma neurose noogênica ou psicogênica, é uma neurose sociogênica, diz Frankl. A neurose sociogênica é consequência de uma sociedade industrializada que cria desarraigamento e alienação de tradições e valores. Esse contexto cria a síndrome da neurose de massa, essa neurose sociogênica, de caráter espiritual, que tem como causa a falta de sentido e que tem como sintomas a depressão, a violência, os vícios, etc. Por isso, ao contrário da psicologia do profundo de Adler e Freud, Frankl sugere a psicologia das alturas. Essa psicologia inclui em sua imagem de ser humano a vontade de espiritualidade e a necessidade de sentido.

Para Jacob Levy Moreno (1983, p. 121), que já em sua época se encontrava incluído em um movimento de renovação psiquiátrica, se antes o problema central era a psicopatologia de seres patológicos (criminosos e pacientes mentais), o problema, nesse momento, estava na "patologia do grupo normal". O grupo psicopatológico de pacientes mentais e criminosos conformam, segundo ele, uma minoria que é apartada do resto da sociedade, ficando em segurança e presa em prisões e asilos. E conclui que 
são pessoas normais que compõem o grupo "responsável pela decadência mental e social geral, pelas guerras e revoluções que já se mostraram não construtivas e incapazes de concretizar as promessas feitas pelos líderes".

A constatação dos autores é de grande validade para uma interpretação do fenômeno religioso e espiritual contemporâneo. Há, por um lado, uma grande frustração com os sistemas religiosos tradicionais e, por outro, uma busca desesperada por experiências religiosas e espirituais, em que se tenta encontrar novos significados, novos valores que possam sustentar a razão de viver. Para Frankl, esse é o contexto da falta de sentido de vida típico de uma época pós-iluminista, racionalista, que havia prometido a superação da religião e a salvação do mundo pela razão e pela ciência. Existe hoje essa percepção sutil, a suspeita por parte do ser humano simples de que a explicação científica também não deu conta de salvar a humanidade da ameaça de ser lançada ao nada, da ameaça do não ser. Ademais, vivemos em uma sociedade de consumo, em que criar já não é tão importante quanto consumir. Sequer é preciso desejar, apenas consumir, o que significa que não mais é necessário que o ser humano se confronte com o seu desejo próprio - consumir o desejo alheio já basta. Repete-se, então, apenas o desejo de um outro ser na ilusão de que este é o desejo espontâneo e próprio. Frustra-se a originalidade do sentido de vida. A angústia e o desespero se instalam no vazio da repetição sem valores profundos e do consumo sem sentido, que se estende inclusive ao consumo de "matéria" espiritual - tudo na ânsia de preencher um vazio que apenas cresce em consequência da superficialidade do conteúdo dos valores consumidos e absorvidos (MERENGUÉ, 2001).

Enquanto Frankl fala da crise de sentido nesse contexto de desarraigamento e Guattari chama a atenção para a deterioração dos vínculos do ser humano com o mundo que o cerca, incluindo desequilíbrios espirituais, psíquicos, sociais e ambientais, Paul Tillich entende que a humanidade do século XX - e que, entendo, se estende ao século XXI - vive um estado de profunda angústia, desespero e alienação. Uma profunda frustração existencial.

Segundo Tillich (1991), na história da civilização ocidental podem ser identificados três grandes períodos de ansiedade nos quais se manifestam três diferentes tipos de ansiedade. No fim da civilização antiga 
predominou a ansiedade ôntica, ansiedade relativa ao destino e à morte, e no fim da Idade Média predominou a ansiedade moral, relativa à culpa e à condenação, em que a autoafirmação moral do ser humano é ameaçada pelo não ser. A ansiedade que afeta a humanidade no fim do período moderno, segundo Tillich, é a ansiedade espiritual, que se expressa pelo sentimento da vacuidade e da insignificação. Esse período inicia no contexto de queda do absolutismo, alicerces do liberalismo e da democracia, e expectativas e promessas de uma civilização técnica, com o Iluminismo e humanismo revelando novas bases religiosas para a sociedade ocidental. Consequência disto é a manifestação de uma ansiedade referente ao não ser espiritual. Evidencia-se aí uma sensação de fragmentação, esfacelamento da totalidade que compõe o ser humano com o mundo que o cerca.

Portanto, a ansiedade que ameaça o ser humano no período da modernidade é a ansiedade espiritual. A minha hipótese aqui é que essa ansiedade afeta a humanidade de modo avassalador até o momento atual. É um sentimento de vacuidade que leva a uma profunda insignificação. "Vacuidade e perda de significação são expressões da ameaça do não ser à vida espiritual” (TILLICH, 1991, p. 37). Na base da insignificação está a vacuidade. É o certo, o seguro, a confiança, um algo que dava sentido, suporte, uma certeza que

se rompe através dos acontecimentos externos ou processos interiores: somos cortados da participação criadora numa esfera de cultura, nos sentimos frustrados a respeito de algo que se tinha afirmado com paixão, somos conduzidos da devoção a um objeto à devoção por outro e de novo por outro, porque o sentido de cada um deles se desvanece e o eros criador se transformou em indiferença ou aversão. Tudo é tentado e nada satisfaz.

Tillich (1991 apud MONDIN, 1980, p. 77) ainda se refere também a um estado de alienação vivido pela humanidade. A predisposição psicológica aponta para a experiência humana da inutilidade do ser, da incapacidade de dar sentido à vida e da alienação da essência - "alienação dos outros e de nós mesmos", "alienação do fundamento do nosso ser, porque nos alienamos da origem e do objetivo da nossa vida. Não sabemos mais de onde viemos e para onde vamos. Estamos separados do mistério, da profundidade, da grandeza do nosso ser". Para Tillich (1967, p. 278), o 
pecado é essa alienação, a qual é preciso trazer à consciência, para que seja superado o "estado de cômoda auto-suficiência, de soberba" que impede a fé. "A fé é a resposta de Deus à questão existencial. Enquanto esta resposta não é colocada, Deus não responde". A resposta de Deus é a Revelação.

A alienação, a autossuficiência, a soberba são resultado de um longo processo de abandono, no qual a criatura tenta se livrar do Ser e nega a pertença e a ligação ao outro ser. A humanidade buscou intensamente uma liberdade, baseada em ideologias que valorizam o ser na sua individualidade. Tratou-se de uma liberdade fictícia, idealizada, baseada em uma suposta autonomia, uma independência e individualidade - que seriam a plenitude do eu. O Eu, o indivíduo, passou a ser o centro do mundo.

O estado de alienação profunda é o estado em que o ser se perdeu e se esqueceu de sua pertença, sua ligação original que sustenta o ser no vazio. Esse esquecimento levou a uma alienação profunda - um não saber de onde veio e para onde vai e ao que (e que) está ligado como ser. O ser humano em sua essência participa do Ser de Deus e o Ser de Deus participa do ser humano. Mas a dinâmica existencial acaba afastando o ser humano do ser-em-si, da sua verdadeira essência, da sua autenticidade. Acontece uma separação do ser humano da sua totalidade.

O fato de o ser humano intuir essa separação, essa queda, essa alienação, faz nascer a religião - que faz o processo de religar o humano com o divino, faz nascer a abertura para uma nova busca de um aprofundamento espiritual. O sentimento de vazio, de falta de sentido, a angústia espiritual é o sentimento de separação, de perda do infinito, da totalidade, porque houve uma separação, um afastamento dos valores supremos, dos sentimentos supremos. Para Tillich, ser humano é ser religioso e ser religioso é buscar resgatar a totalidade e a essência primordial. A relação do ser humano com o mundo e com o seu próximo é permeada pela dimensão do sagrado. Trata-se da aceitação de uma força que permeia a existência e que transcende o ego e que impulsiona o ser humano para algo que é a totalidade no ser em si.

Segundo Zerka Moreno (2001), a sociedade humana se caracteriza pela interdependência entre quem dela faz parte, não pelo desligamento, pela independência ou o puro autocentramento. Nenhum ser vivo é capaz de viver e sobreviver no isolamento. A interdependência, a relacionalidade 
de tudo com tudo, e de forma singular da humanidade entre si, é a própria vida do cosmos, e a capacidade de manter esses vínculos de tudo com tudo e das pessoas entre si é que vai resultar na vida sadia. Sobrepor o valor da independência à relacionalidade na sociedade pode ter sérias consequências para a humanidade. A independência pode levar à carência, à negação da necessidade de dar e receber afeto, ao isolamento, ao autoritarismo, à dominação, e por fim à psicopatia. Para Zerka, o oposto da dependência pode ser interdependência.

Viktor Frankl nos dirá que o ser humano é responsável pelo sentido potencial da sua vida. O verdadeiro sentido deve ser descoberto no mundo e não dentro da pessoa humana ou da psique. Esta aponta e orienta o ser humano para algo diferente de si mesmo. O autor indicará que o sentido de vida pode se realizar por três vias principais: por meio da criação, de uma obra, do trabalho, de uma ação, algo que leve o ser humano a se confrontar com a sua capacidade criativa, pela qual se encontrará consigo mesmo, seu ser; por meio do amor, da descoberta da capacidade de amar, experimentando algo, vivenciando algo muito especial; e por meio do sofrimento, isto é, por meio da atitude em relação ao sofrimento. Apesar do sofrimento que pode acometer o ser humano, ele ainda é capaz de encontrar um sentido, e justamente o sentido mais elevado. Mesmo diante de um destino que não pode ser mudado, uma pessoa pode "erguer-se acima de si mesma, crescer para além de si mesma e, assim, mudar-se a si mesma” (FRANKL, 1992, p. 124). Essa tríade de possibilidades de sentido Frankl também nomeará como valores de criação, valores de vivência e valores de aceitação.

\section{O ser criativo e a realização espiritual}

Criatividade é a realização da infinitude do ser na presença criativa do Ser. A criatividade e a fé - ambas emanam do centro do Ser. Ambas são o centro mais original do ser humano e ambas ligam o ser humano ao transcendental, ao supremo, ao profundo, ao divino. A transcendentalidade é a realização da totalidade, o encontro do humano com o divino, do divino com o humano - o totalmente outro. Ambas relembram o ser humano de sua pertença e de sua ligação. Por meio da criatividade a 
criatura se lembra de que é um ser criado e essa memória a liga a um Ser supremo. O Ser supremo cria a criatura e a vocaciona com o dom da fé e o dom da capacidade criativa. Coloca-lhe no centro algo da imagem e algo da semelhança com o Ser e essa imagem e semelhança torna a criatura um ser criativo capaz de criar, de recriar, de cuidar - e capaz de crer. Crer para além de si. Crer para além do imediato, do humano, do finito. A busca da realização da imagem e semelhança é a orientação para o transcendente é a profunda busca por sentido.

Se o ser criado se torna incapaz de criar, ele se torna infeliz, frustrado, não realizado justamente por não realizar a sua vocação original - a de ser um ser criador, e uma criatura de sentido, que busca sentido para sua existência. A capacidade de criar é uma capacidade transcendental porque ela permite justamente criar e recriar a vida em suas diferentes dimensões, incluindo o que tange à vida relacional. O ser que não realiza a sua vocação de fé torna-se igualmente infeliz, frustrado. E isso podemos encontrar hoje na tão desesperada busca por espiritualidade, religião e igrejas em nosso meio. Uma fé negada ou superficial é uma fé não realizada, transcendentalidade frustrada.

Frankl (1992) considera que dentro da espiritualidade inconsciente existe uma religiosidade inconsciente - um relacionamento inconsciente com Deus, uma relação com o transcendente - que é imanente, que muitas vezes fica latente. Trata-se de um inconsciente espiritual e transcendente. A fé inconsciente está incluída no conceito de seu inconsciente transcendente, o que significa, segundo o autor, que sempre houve uma tendência inconsciente para Deus. Significa que Deus às vezes permanece inconsciente para nós. Nossa relação com Deus pode ser inconsciente, reprimida e oculta para nós mesmos. Para Frankl, a religiosidade inconsciente e todo inconsciente espiritual constituem um ser inconsciente que decide, mas não um ser impelido a partir do inconsciente. Para o autor, o inconsciente espiritual e a religiosidade inconsciente, ou seja, o inconsciente transcendental, não são um inconsciente determinante, mas existente. Essa religiosidade inconsciente provém do centro do ser, da própria pessoa. Não é inata, não é biológica. Se para Freud a religião é a neurose obsessiva da humanidade, para Frankl a neurose obsessiva é uma religiosidade psiquicamente doente. Quando a fé se distorce, se desfigura - 
quando o sentimento religioso se torna vítima de uma repressão por parte da razão despótica, de uma inteligência técnica -, a deficiência da transcendência vinga-se por meio de uma existência neurótica.

Viver a vida em sua dimensão criativa e espiritual é simplesmente realizar a vida em suas múltiplas e diferentes dimensões. E realizar a vida é realizá-la em sua dimensão e vocação mais suprema e profunda. É a realização do sentido que a vida espera que nós sejamos capazes de lhe conferir. A energia criativa que move o ser é parte da mesma vocação que a fé e compõe a totalidade do ser. A dimensão criativa, a força criadora do cosmos participa da mesma energia primordial que sustenta o ser humano em sua totalidade.

Uma das experiências de diálogo mais profícuas entre a teologia e a psicologia pode ser encontrada na obra de Jacob Levy Moreno, criador da psicoterapia psicodramática - o psicodrama. ${ }^{1}$ Moreno é um raro teórico que consegue reunir no mesmo sistema de pensamento a dimensão criativa e espiritual do ser humano. Recorrendo a conhecimentos religiosos, ele constrói a partir de conceitos teológicos uma teoria interdisciplinar.

A família de Moreno era de origem judaica, mas teve também uma educação cristã por influência de sua mãe, que teve formação em um convento católico. Em sua juventude, Moreno tomou parte do movimento judaico hassídico. ${ }^{2}$ A sua formação religiosa influenciou sua vida e a base dos métodos de psicoterapia de grupos que desenvolveu. Essa formação religiosa abre Moreno para a dimensão divina cósmica do mundo. O hassidismo pregava a humildade, a piedade, a imanência - universalidade da

10 psicodrama é uma teoria e um método para o trabalho psicoterapêutico com grupos criado por Jacob Levy Moreno. Drama é um termo de origem grega e significa ação, "ou algo que acontece". Moreno definiu o psicodrama como "o método que penetra a verdade da alma através da ação" (MORENO, 1993), ou como um processo que "explora a verdade por meio de métodos dramáticos" (MORENO, 1983). A verdade não é a verdade universal, fixa, última, mas a que é justa para um determinado contexto, relação ou pessoa.

20 hassidismo surge dentro do judaísmo por volta de 1750, e estende a prática religiosa ao âmbito mais popular, tornando a vida cotidiana espaço de santificação - para além dos templos e orações específicas. 0 sagrado e o profano se diluem de sua rígida separação. É um movimento que se preocupa com a devoção, a santificação e a inclusão de todo ser na graça de Deus. Os mestres hassídicos saem dos templos e pregam, junto à natureza, a criação de Deus. Moreno se inspira em Jesus, Buda, São Francisco de Assis, Santo Agostinho, Mestre Eckardt, Zohar e Zerirah, Swedenborg, (místico sueco), etc.; conhecia a mística judaica, além da formação religiosa hassídica (NUDEL, 1994, p. 35). 
presença divina; afirmava que "ninguém é irrecuperável. E a recuperação do pecado, que é o resgate de uma 'centelha decaída', causa o júbilo de Deus, cujo radioso reflexo volta a iluminar, na face mais obscurecida e deformada, a semelhança divina" (NUDEL, 1994, p. 35). A partir dessa concepção se pode compreender a extrema bondade que Moreno passou a dedicar às pessoas que padeciam de sofrimentos psíquicos e que por isso eram excluídas socialmente. Desde jovem Moreno pesquisou com grupos de crianças, mulheres, em campos de pessoas refugiadas e escolas com regime de internato. E mais tarde justificou:

Segui o caminho do teatro em lugar de fundar uma seita religiosa entrando num mosteiro, ou desenvolvendo um sistema teológico [...]; isso pode ser entendido dando-se uma olhada para onde minhas idéias se originaram. Eu tinha uma idéia fixa, ou o que então poderia ser chamado de afetação, mas que hoje, quando os resultados estão chegando, poderia ser visto como a graça de Deus. A idéia fixa tornou-se minha constante fonte de produtividade: há um tipo de natureza primordial que é imortal e retorna renovada a cada geração, um primeiro universo que contém todos os seres e no qual todos os eventos são sagrados (NUDEL, 1994, p. 78).

As suas brincadeiras quando criança, os posteriores encontros com as crianças nos jardins de Viena, seu trabalho com prostituas, a Casa de Acolhida criada para pessoas refugiadas, o trabalho no acampamento de refugiados, tudo isso levou Moreno a acreditar profundamente numa ideia de encontro de cura. Esse encontro seria uma forma de salvação da pessoa, no sentido teológico, que seria, conforme Moreno intuía, como "um encontro com a Divindade, o Criador, durante o drama" (MORENO, 2001, p. 86), no encontro do grupo terapêutico. O trabalho dedicado a esses grupos enquanto ainda era jovem, e depois enquanto estudante de medicina e psiquiatria, fez Moreno acreditar que "um indivíduo isolado não possuía autoridade para se transformar na voz de um grupo. A voz nova deve vir do grupo. Deve ser o grupo. A nova palavra deve vir do grupo" (NUDEL, 1994, p. 79).

Em 1936, Moreno criou um hospital psiquiátrico em Beacon, EUA, onde pudesse experimentar e exercitar suas ideias, que entravam em choque com as correntes tradicionais da psicoterapia. O hospital veio a ser 
o Moreno Sanatorium (MARINEAU, 1992), onde Moreno construiu um espaço para o trabalho com psicodrama.

O hospital recebeu muitos pacientes, sendo a maior parte deles casos muito difíceis, rejeitados por outros psiquiatras. Começou a funcionar como uma comunidade terapêutica, lembrando o grupo fundado por Moreno e seus amigos estudantes em Viena, ou seja, a "Casa do Encontro". [...] O sanatório veio a ser como que uma ampla igreja, que incorporava toda pessoa significativa, real ou imaginária, paciente ou não, numa nova filosofia de relações interpessoais (MARINEAU, 1992, p. 140).

$\mathrm{Na}$ opinião de Moreno, a psicoterapia moderna se confronta com dilemas que antes estavam ao alcance da religião, mas de cujas considerações os terapeutas não mais podem se furtar. As angústias humanas coletivas diante da "possibilidade de um naufrágio da humanidade e de o mundo deixar de existir" não podem ser ignoradas ou resumidas a delírios ou alucinações. Permanece a pergunta pelo sentido da vida para a qual a psicoterapia e a religião precisam orientar o ser humano. A pergunta de Moreno é inquietante para aqueles métodos pouco interdisciplinares: "como se deve comportar um terapeuta em um universo desumano frio e indiferente em relação existência do homem (sic)? Poderá o terapeuta se recusar a responder ou responder: 'Eu não sou sacerdote, nem mágico, sou apenas um médico?' Onde se inicia a medicina psicoterápica e onde termina ela? Quem tem a responsabilidade de se ocupar com essas necessidades profundas, que podem surgir no decorrer de sessões terapêuticas, senão o psicoterapeuta?" (FOX, 2002, p. 16).

Viktor Frankl, como Moreno, não se esquiva da crítica aos limites estanques assumidos pelas ciências e pela religião. Para ele, a psicologia profunda esqueceu o plano ontológico (do ser), atendo-se apenas ao plano psicológico. "Ninguém que seja honesto e leve a psicoterapia a sério, pode jamais se esquivar do confronto com a teologia - nem hoje, nem há 25 anos atrás" (FRANKL, 1992, p. 12). O autor reitera que o objetivo da psicoterapia é a cura psíquica/cura da alma, enquanto o objetivo da religião é a salvação da alma. Ainda que a religião não tenha pretensão de higiene psíquica, ela é mais que profilaxia psicossomática. Mesmo que não tenha intenção, 
ela tem efeitos psico-higiênicos e psicoterapêuticos, pois propicia proteção e ancoramento. Isso também ocorre na psicoterapia quando o paciente encontra fontes soterradas de uma fé original, inconsciente e reprimida.

Para Moreno, o psicodrama tem uma dimensão cósmica e espiritual. Sua ideia era a de que o ser humano não é apenas um indivíduo separado de outros, mas é um ser ligado a outros, e por isso seu sofrimento e sua cura deveriam se dar de forma mútua. Muito sofrimento é gerado em circunstâncias relacionais e a cura, portanto, é também a cura de situações relacionais. A nossa existência é relacional, social e cósmica.

Enquanto Freud via o psiquismo como uma esfera individual e atrelava a energia psíquica à libido, Moreno entendia que a energia psíquica não era individualizada, compartimentalizada, mas fluía entre as pessoas, no grupo e no cosmos, promovida pela espontaneidade e pela criatividade. "Somos mais do que seres econômicos, psicológicos, biológicos ou sociológicos, somos, primeiro e acima de tudo, seres cósmicos. Somos provenientes do cosmos e a ele retornaremos. [...] A voz de Deus encontra-se em todos nós" (MORENO, 1992 apud MORENO, 2001, p. 16).

O ser humano moreniano é um ser espontâneo-criador, um ser de vínculos, um ser cósmico. A espontaneidade e a criatividade serão as fontes de energia que facilitarão a vida saudável, as ações e comportamentos inovadores do ser. Aquelas fontes serão capazes de impedir a conservação em modelos opressores e estáticos. Com essa energia em plena atividade é que o ser humano terá a capacidade de criar e recriar sua vida cotidiana.

Cada "eu" é um ser divino, criado à imagem e semelhança de Deus, dotado de dons criativos para o mundo relacional. O ideal terapêutico de Moreno é religar o ser humano "com o Deus perdido, ajudando-o a sair do servilismo a falsos ídolos da 'conserva cultural"' (BUSTOS, 2002, p. 18). ${ }^{3}$ Toda pessoa nasce dotada de potenciais criativos, espontâneos, de sensibilidade, e de capacidade para desenvolvê-los de forma não destrutiva. No entanto, os fatores que contribuem para a vivência plena desses

3 Moreno criou o conceito conserva cultural para explicar e nomear as estruturas criadas para manter conservado o que já se criou. A sociedade ampara-se de forma que mudanças sejam extremamente dificultadas a fim de que a espontaneidade encontre poucas vias de sobrevivência e expressão. 0 ser humano anseia tanto a sua participação espontânea na vida do cosmos quanto a segurança passiva da conserva que exige a permanência do que está.

Rev. Pistis Prax., Teol. Pastor., Curitiba, v. 3, n. 2, p. 333-359, jul./dez. 2011 
potenciais podem ser atrapalhados por acontecimentos, ambientes, ou sistemas sociais desfavoráveis. Quando isso acontece, é preciso recorrer a alternativas que auxiliam a reencontrar os "fatores vitais" perdidos, por meio da revisão e mudança nas relações afetivas, e por meio de ações que provocam mudanças no ambiente.

Moreno compreende o ser humano "a partir de uma 'célula' mínima: o vínculo - unidade indivisível de seu meio ambiente. Não existe o 'eu sou', e sim o 'eu sou em relação a'” (CUSCHNIR, 1992, p. 77). A saúde de uma pessoa depende da saúde de seus vínculos com outros seres humanos e com todo o cosmos. Para compreender o sofrimento de um ser é preciso investigar suas relações, seus vínculos e o ambiente-mundo desse ser. Muitos vínculos são assimétricos e, nesses casos, afetam a espontaneidade e a capacidade criativa, a capacidade de recriar e criar coisas, situações e relações novas, vínculos novos. Nesse espaço, a tentativa psicoterapêutica de Moreno é capacitar e recuperar essa capacidade humana de criar e recriar os seus vínculos para viver com mais dignidade e plenitude.

Moreno desenvolveu a sua teoria psicoterapêutica para contextos de grupos, pois acreditava que o grupo, além de uma microssociedade, era também um passo para dentro do mundo/cosmos. O grupo tem uma dimensão social, a pessoa no grupo faz uma experiência nova e confronta sua experiência antiga num espaço que tem um caráter social. Moreno pergunta pela existência de "uma forma cósmica de compreensão", porque, para ele, o ser humano é um ser cósmico.

É mais do que um ser psicológico, biológico e natural. Pela limitação da responsabilidade do homem (sic) aos domínios psicológicos, sociais ou biológicos da vida, faz-se dele um banido. Ou ele é também responsável por todo o universo, por todas as formas do ser e por todos os valores, ou sua responsabilidade não significa absolutamente nada. A existência do universo é importante, é realmente a única existência significativa; é mais importante que a vida e a morte do homem (sic) como indivíduo, como tipo de civilização, como espécie. Depois da "vontade de viver" de Schopenhauer, a "vontade de poder" de Nietzsche, e "vontade de valer" de Weininger, eu partilho a "vontade do valor" que todos os seres pressentem e que os une a todos. Daí coloquei a hipótese de que o Cosmo em devir é a primeira e última existência e o valor supremo. Apenas ele pode atribuir sentido à vida de qualquer partícula do universo, seja o homem 
(sic) ou um protozoário. A ciência e os métodos experimentais, se têm pretensão a serem verdadeiros, precisam ser aplicáveis à teoria do cosmo (MORENO, 1993, p. 15).

Não nos mesmos termos, mas de maneira muito afinada com Moreno - que aponta a dimensão cósmica do ser humano, o eu divino e o "eu sou em relação a", além da religação do humano com o Deus perdido -, Frankl (2001, p. 77-78) considera que a característica ontológica fundamental da realidade humana é a "autotranscendência da existência". "Ser humano significa dirigir-se para além de si mesmo, para algo diferente de si, alguma coisa ou alguém". O interesse maior do ser humano, segundo o autor, não é por suas questões internas - prazer ou equilíbrio. "O ser humano é orientado para o mundo fora de si - além de si. Pela auto-compreensão pré-reflexiva o ser humano tem conhecimento de que a auto realização se dá na medida em que ele esquece de si mesmo".

Moreno e Frankl apontam de modo semelhante para a vontade do valor supremo ou do sentido supremo. Segundo Frankl, a mais humana de todas as necessidades é a necessidade de sentido, a vontade de sentido. É essa vontade de sentido que hoje está tão frustrada no ser humano. Ao contrário da psicologia do profundo de Adler - que também sustenta a vontade de poder do ser humano -, e de Freud - que sustenta a vontade de prazer -, Frankl, ao propor a psicologia das alturas, inclui em sua imagem de ser humano a necessidade de sentido. Trata-se de um sentido último, que não é acessível à razão ou à inteligência pura. Diante de tal questão de sentido não há resposta intelectual, mas é possível uma decisão existencial. Quem decide por ela assume que a vida tem um sentido infinito, um suprassentido que está além da nossa capacidade finita de compreensão. Os sentidos universais são chamados de valores, pois há sentidos universais implicados nos valores. Estes últimos são sentidos universais abstratos, e estão além da situação particular que dá sentido.

\section{Encarnação e criação}

Encarnação se refere à opção de Deus pela humanidade - quando Deus se torna humano, quando Deus se aproxima da humanidade através 
de Jesus Cristo. Jacob Levy Moreno importa o conceito "encarnação" da teologia cristã para sua teoria no campo da psicologia. Moreno reconhece o fato da criação do ser humano por Deus e a semelhança entre Criador e criatura, descrita no livro bíblico do Gênesis, bem como reconhece o fato da encarnação de Deus em Jesus Cristo, que reinicia a proximidade de Deus com a sua criação.

Interrogado por teólogos sobre a diferença entre a sua proposta e o exercício do amor cristão, Moreno respondeu: "bem, nós não avançamos muito, realmente, em relação ao 'Ame seu próximo', salvo por termos acrescentado 'mediante a inversão de papéis"” (FOX, 2002, p. 39). Moreno discordava da oposição entre religião e ciência. Para ele, "o futuro da ciência repousa na sua integração com uma filosofia de Deus. [...] Cada ser humano para Moreno é Deus enquanto criador e co-criador" (MARINEAU, 1992, p. 122). A imagem moreniana de Deus não é uma imagem estática, uma entidade; é uma imagem que evidencia a criatividade, o processo da criação constante; é "um símbolo de fluidez". Criar o ser humano "significa exercitar radicalmente sua essência, a abertura, a disruptura, a mutação. Deus mutante que precisa de seres mutantes" (MERENGUÉ, 2001, p. 72). A arte de criar é uma capacidade divina e humana.

No movimento de criatividade e espontaneidade, esta última irá desencadear a "consciência corporal e abertura ao mundo" e novamente capacitar o dom criativo primordial de cada ser criado à imagem de Deus. A criatividade é um movimento, é uma dimensão ativa, uma energia não mórbida. Assim, o ato da encarnação, em que Deus se torna carne, é em si um ato criador-criativo, recriador. É o movimento criativo por iniciativa divina, da mesma forma como está descrito no Gênesis, que testemunha o Ser criativo da divindade. "Descrever o fenômeno da encarnação é descrever a própria dinâmica do esforço criador” (NETO, 1999, p. 74). Encarnar é criar e recriar desde a imagem divina, a partir do Ser divino que desperta para a necessidade do mundo, dos seres, das relações. "Moreno pretende que essa encarnação não seja privilégio de alguns indivíduos, mas que seja estendida a qualquer indivíduo" (MORENO, 1992 apud NETO, 1999, p. 78). Por meio do psicodrama, 
qualquer pessoa pode pintar sua versão de Deus através de suas próprias ações e, assim, comunicar sua própria versão aos outros. [...] Líderes, profetas e terapeutas de todos os tempos sempre tentaram representar Deus e tentaram impor sobre as pobres pessoas, o pequeno homem, seu poder e superioridade magníficos. No mundo psicodramático os quadros se invertem. Não é mais o senhor, o grande sacerdote ou o grande terapeuta que encarnam Deus. A imagem de Deus pode tomar a forma e ser encarnada por qualquer pessoa - o epilético, o esquizofrênico, a prostituta, o pobre e o rejeitado. Todos podem, a qualquer momento, subir no palco quando surgir o momento de inspiração e dar uma versão do significado que o universo tem para eles. Deus está sempre dentro e entre nós, como está para as crianças. Em vez de descer dos céus, ele entra pela porta do palco" (MORENO,1992 apud NETO, 1999, p. 78)

Moreno interpreta e atua a teologia da Criação e da Encarnação por meio do psicodrama. Além disso, a crença de Moreno expressava uma fé profunda na graça e bondade de Deus que salva toda criatura, o que se evidencia no exercício da bondade do próprio Moreno e de sua fé em relação à cura de pessoas com profundo sofrimento psíquico. O Deus de Moreno é, portanto, um Deus-junto, próximo, que se encarnou, que criou e cria ainda e sempre, e que salva. A encarnação de Deus em Jesus Cristo torna explícito à humanidade o sofrimento divino, a humildade divina e a proximidade da divindade com a humanidade. O sofrimento humano é ponto de partida para a encarnação de Deus, para a recriação da vida em vida nova. "O psicodrama abandona o Super-Deus cósmico, irrealizável, pela presença carnal do filho de Deus: Jesus Cristo, símbolo da própria encarnação" (NETO, 1999, p. 81). Como método, reconhece a presença de Deus no instante em que reconhece o sofrimento humano e o respeita, e oferece à pessoa e ao mundo que sofre um lugar onde a vida pode ser recriada, a exemplo da divindade que cria e recria a vida. Há que se levar em conta que

a afirmação de Moreno de que criar significa encarnar Deus contrapõe-se a uma outra: a de que o esforço criador desemboca sempre em realizações parciais, pois o homem (sic) é, antes de tudo, corpo, contingência, momento, espontaneidade; habita um mundo que se transforma continuamente e onde nenhuma realização pode ter um caráter mais universal do que o da própria situação onde surgiu, onde cada produto criado não representa senão a matéria prima para um novo ato criador e assim sucessivamente. 
O lado divino do ser humano não é, pois, uma coincidência tanto mais perfeita ou tanto mais completa como uma Totalidade Divina, mas sua capacidade de lançar-se nesse movimento de auto-superação infinito, esse sem-fim que é o próprio Deus moreniano: princípio indefinível, movimento puro incapaz de conter em si qualquer atributo, pois é, em si, a superação contínua de qualquer um deles com o qual se queira designá-lo (por exemplo: Deus-bondade, Deus-sabedoria, Deus-justiça, etc).

O hassidismo postula a espontaneidade e a criatividade como uma dimensão do ser humano a ser cultivada. A revelação de Deus, segundo esse movimento, se dá na comunicação, na ação, no cantar, no dançar... O movimento praticamente ocupa o lugar da contemplação, o templo dá lugar para espaços variados como os jardins, a copa da árvore, a casa da prostituta.

Seja buscando na figura de Cristo um símbolo, seja reencontrando nos preceitos hassídicos uma espécie de mola propulsora, o caminho que Moreno nos aponta é sempre o mesmo: uma intensa valorização do corpo em relação, do corpo comprometido com o mundo, onde o conceito de encarnação não faz mais que exprimir essa forma fundamental do ser humano: ser en-carnado, ser em-carne, ser feito-carne (NETO, 1999, p. 83).

\section{0 momento de criar}

É no contexto conflituoso da Primeira Guerra Mundial e em seus rastros que Moreno percebe e propõe a categoria do momento - como um grito de esperança em meio a um tempo em que "as conservas culturais alcançaram um tal ponto de desenvolvimento e massificação que se tornaram um desafio e uma ameaça à sensibilidade dos padrões criativos" do ser humano (FOX, 2002, p. 82).

A filosofia do momento tem como pressuposto teológico a Teologia da Criação. Compreende a divindade em sua função de criadora do universo, em sua essência criativa. Está atenta ao tempo criativo, ao espaço do ato da criação, como na imagem da divindade que cria durante sete dias, depois descansa, mas não cessa de criar e recriar. Segundo Moreno, 
o "atributo de Criador" de Deus foi negligenciado pelas religiões em detrimento de outros atributos tais como justiça, onisciência, onipotência, bondade. Esses atributos, que conformam o status de Deus perante a humanidade, são os que em grande parte consolidam a imagem de Deus após a criação. Moreno, então, se volta ao grande instante da divindade no momento da criação, no parto da criação. É o processo de criação que entra em questão, o próprio parto daquilo que vai nascer que lhe interessa: "existe um outro status de Deus que, mesmo como símbolo, foi negligenciado: é o seu status antes do Sabath, a partir do momento da concepção, durante o processo de criação e desenvolvimento dos mundos e de Ele Mesmo"; o momento é "o momento de ser, viver e criar" (MORENO, 1975, p. 155). Sete dias foi um tempo/momento de intensa espontaneidade e criatividade da divindade criadora. Depois houve tempo de descanso. Depois houve sempre, e eternamente continuam os momentos criativos, tempos e momentos de criação e recriação de mundos.

Segundo Moreno, a imagem de Deus que permaneceu e influenciou as nossas ciências e culturas é a imagem de um Deus velho, cansado, perfeito, sábio, distante. Essa imagem não coincide com a imagem de Deus no começo e durante a criação, mas é a imagem de Deus pós-criação e uma imagem que prevê Deus mediante uma obra acabada. Mesmo que Deus tenha visto que tudo era bom, que criou o mundo em sete dias, o sétimo dia era apenas de descanso. O próprio descanso fez, então, parte de sua obra. "A mesma estratégia de preferência, isto é, a preferência do segundo estado contra o primeiro estado do mito bíblico, é experimentada na atitude do homem (sic) para consigo mesmo, suas artes, sua moral, suas formas de cultura, sociedade e governo" (MORENO, 1975, p. 81). O último estágio da criação, a obra pronta, é a que fascinou e fascina o ser humano. A obra pronta é idolatrada, seja ela o livro, o filme, a escultura, o produto no supermercado, as ideias, os modelos morais. Assim, estabeleceu-se a obra e, além dela, o ser que cria - ser humano ou Deus, em seu poder relacionado com sua criação -, como autoridade, ao lado da criação, e ambas, criatura e ser que cria, como produtos acabados.

A percepção e atenção especial de Moreno ao processo criativo e não à obra concluída, leva-o a propor a categoria do momento como um referencial para o contexto terapêutico. O momento é o ato, o processo, o 
instante da criação de algo novo. O momento criativo é puro improviso. A relevância da improvisação é o oposto da relevância de um resultado dogmático, dos conteúdos criados e prontos. A conservação e o valor dos resultados do que é criado é sobremaneira relevante na civilização moderna.

A filosofia do momento se propõe à minuciosa observação e pesquisa a fim de compreender o espaço da criação no ser, o tempo e o momento da criação de algo, o romper da espontaneidade, a erupção criativa. Para Paul Tillich, seria a ruptura do não ser para o ser. Abertura do ser para o Ser, para a existência mais plena, realização da totalidade. O momento é o lugar onde algo nasce. Nasce algo que vai existir de forma nova. Uma relação ressignificada, uma compreensão nova da existência, do modo de conviver, de novas palavras, novos mundos. A vida do ser em conformidade com as conservas culturais é viável, mas é árida como as próprias conservas em que a energia criativa não mais tem movimento em momentos germinadores - os estados de criatividade e espontaneidade.

\section{Consideração final}

A angústia e a frustração da humanidade e a consequente busca de um valor ou um sentido supremo para a vida são as grandes questões latentes que querem vir à tona, e que se manifestam neste auge ou abismo de um sofrimento que afeta a massa humana neste momento da história. A falta de sentido e a angústia espiritual são sofrimentos de uma humanidade que vive um estado de profunda alienação em relação à sua condição de criatura vinculada ao ser/Ser e ao cosmos. Essa condição de criatura vinculada foi longamente negada e reprimida, e a angústia espiritual é a angústia pela realização da totalidade, pela sua capacidade de criatura criativa. Trata-se também da uma reabilitação da dimensão espiritual tão longamente negligenciada pela ciência de caráter positivista. Por essa razão, é fundamental o aporte de autores como os aqui tratados que ultrapassaram a divisa do preconceito das ditas ciências naturais com as ciências do espírito. 


\section{Referências}

BOFF, L. Espiritualidade, dimensão esquecida e necessária. Disponível em: <www.leonardoboff.com/site/espiritualidade.htm>. Acesso em: 22 jun. 2009.

BUSTOS, D. M. Novos rumos em psicodrama. São Paulo: Ática, 1992.

CARLOS, S. A. O processo grupal. In: STREY, M. N. et al. Psicologia social contemporânea. Petrópolis: Vozes, 1998. p. 199-206.

CUSCHNIR, L. Masculino/Feminina. Rio de Janeiro: Rosa dos Tempos, 1992.

FOWLER, J. Estágios da fé. São Leopoldo: Sinodal, 1982.

FOX, J. 0 essencial de Moreno: textos sobre psicodrama, terapia de grupo e espontaneidade. São Paulo: Ágora, 2002.

FRANKL, V. E. Em busca de sentido. 14. ed. São Leopoldo: Sinodal; Petrópolis: Vozes, 2001.

FRANKL, V. E. A presença ignorada de Deus. São Leopoldo: Sinodal; Petrópolis: Vozes, 1992.

FRANKL, V. E. Sede de sentido. 3. ed. São Paulo: Quadrante, 2003.

GUATTARI, F. As três ecologias. 17. ed. São Paulo: Papirus, 1990.

GUATTARI, F.; ROLNIK, S. Micropolítica: cartografias do desejo. 5. ed. Petrópolis: Vozes, 1999.

MAFFESOLI, M. 0 tempo das tribos: o declínio do individualismo nas sociedades de massa. Rio de Janeiro: Forense-Universitária, 1987.

MARINEAU, R. F. Jacob Levy Moreno, 1889-1974: pai do psicodrama, da sociometria e da psicoterapia de grupo. São Paulo: Ágora, 1992.

MERENGUÉ, D. Inventário de afetos: inquietações, teorias, psicodramas. São Paulo: Ágora, 2001.

MONDIN, B. Os grandes teólogos do séc. XX. São Paulo: Paulinas, 1980. v. 2.

MORENO, J. L. Psicodrama. São Paulo: Cultrix, 1975. 
MORENO, J. L. Fundamentos do psicodrama. 2. ed. São Paulo: Summus, 1983. MORENO, J. L. Psicoterapia de grupo e psicodrama: introdução à teoria e prática. 2. ed. rev. Campinas: Psy, 1993.

MORENO, Z.; BLOMKVIST, L. D.; RÜTZEL, T. A realidade suplementar e a arte de curar. São Paulo: Ágora, 2001.

NETO, A. N. Psicodrama: descolonizando o imaginário. São Paulo: Brasiliense, 1979.

NUDEL, B. W. Moreno e o hassidismo. São Paulo: Ágora, 1994.

TILLICH, P. Teologia sistemática. São Leopoldo: Sinodal; São Paulo: Paulinas, 1967.

TILLICH, P. Coragem de ser. São Paulo: Paz e Terra, 1991.

TILLICH, P. Dinâmica da fé. 4. ed. São Leopoldo: Sinodal, 1992.

VALLE, J. E. Religião e espiritualidade: um olhar psicológico. In: AMATUZZI, M. M. Psicologia e espiritualidade. São Paulo: Paulus, 2005. p. 83-107.

Recebido: 17/12/2010

Received: 12/17/2010

Aprovado: 19/01/2011

Approved: 01/19/2011 